\title{
Article
}

\section{An integrative review exploring the experiences of service users carrying a diagnosis of personality disorder and student mental health nurses and the time they share together}

Jones, Emma, Wright, Karen Margaret and Mckeown, Michael Available at http://clok.uclan.ac.uk/35498/

Jones, Emma ORCID: 0000-0002-2153-2781, Wright, Karen Margaret ORCID: 0000-0003-0693-7294 and Mckeown, Michael ORCID: 0000-0003-0235-1923 (2020) An integrative review exploring the experiences of service users carrying a diagnosis of personality disorder and student mental health nurses and the time they share together. Nurse Education Today . p. 104659. ISSN 0260-6917

It is advisable to refer to the publisher's version if you intend to cite from the work. http://dx.doi.org/10.1016/j.nedt.2020.104659

For more information about UCLan's research in this area go to http://www.uclan.ac.uk/researchgroups/ and search for <name of research Group>.

For information about Research generally at UCLan please go to http://www.uclan.ac.uk/research/

All outputs in CLoK are protected by Intellectual Property Rights law, including Copyright law. Copyright, IPR and Moral Rights for the works on this site are retained by the individual authors and/or other copyright owners. Terms and conditions for use of this material are defined in the policies page. 


\title{
AN INTEGRATIVE REVIEW EXPLORING THE EXPERIENCES OF SERVICE USERS \\ CARRYING A DIAGNOSIS OF PERSONALITY DISORDER AND STUDENT MENTAL \\ HEALTH NURSES AND THE TIME THEY SHARE TOGETHER
}

\begin{abstract}
$\underline{\text { ABSTRACT }}$
Objectives: This integrative review provides a collective understanding of the experiences of student mental health nurses and service users carrying a diagnosis of personality disorder and the time they share together.

Design: Published studies about the time service users and students share together were systematically selected in order to integrate their findings in a thematic analysis.

Data sources: Various databases were searched from 1984 until 2020. Specific search terms were used.

Review methods: 37 studies were included in the integrative review. The studies were from peer reviewed nursing, student, psychology and health related journals. A quality appraisal was completed using Walsh and Downe (2006) framework.

Findings: Four themes emerged from a thematic analysis of the integrative review. These were;

1. 'Psychosocial skills'

2. 'Relationships'

3. 'Environment'

With 'Impact of time' as an overarching theme.

Conclusion: A positive environment which considers time and focuses on seeing the person, as an individual can lead to the development of therapeutic relationships; a core element of the Nursing and Midwifery Council standards for nursing registration in the UK (Nursing and Midwifery Council, 2018). Students attempting to build such relationships need to be mindful of service users' and their own attachment experiences and the impact these can have on experiences of transference and countertransference, particularly for service users carrying a
\end{abstract}


personality disorder diagnosis. It is important for students to be aware of the supportive impact of positive environments and how doing 'everyday stuff' can make a person feel human despite residing in potentially dehumanising places.

\section{KEYWORDS}

Time, service users, students, personality disorder, experiences, relationships, Nursing and Midwifery Council proficiencies

\section{$\underline{\text { HIGHLIGHTS }}$}

- A positive environment which considers time and focuses on seeing the person, can lead to the development of therapeutic relationships; a core element of the Nursing and Midwifery Council standards for nursing registration in the UK.

- Students attempting to build such relationships need to be mindful of service users' and their own attachment experiences and the impact these can have on experiences of transference and countertransference, particularly for service users carrying a personality disorder diagnosis.

- It is important for students to be aware of the supportive impact of positive environments and how doing 'everyday stuff' can make a person feel human despite residing in potentially dehumanising places. 


\section{BACKGROUND}

The experience of the 'time' students and service users share together in mental health services is an area that has not been specifically explored before. Other studies have explored experiences of the 'relationship' (Aiyegbusi \& Kelly, 2015; Hörberg, Brunt, \& Axelsson, 2004; Jones \& Wright, 2017; Walton \& Blossom, 2013) but clearly assume that a relationship exists, and such studies also focus solely on the participants' experiences of the relationship rather than experiences of the wider time together. Students are both the present and future of nursing, and they often have greater contact with service users compared with registered nurses (Jones \& Black, 2008; Mukumbang \& Adejumo, 2014). They are new and fresh into nursing and may not have developed engrained views that some qualified practitioners have (Bowers, Alexander, Simpson, Ryan, \& Carr-Walker, 2007). More importantly service users welcome interactions with students and find their presence facilitative (Morgan \& Sanggaran, 1997; Mukumbang \& Adejumo, 2014). The temporal nature of helping relationships and the passage of time in certain care settings has hitherto been remarked upon (Chandley, 2000) but not with respect to service users and student encounters. It is therefore important to consider experiences of the time service users and students share together.

'Service users', 'patients', 'clients', 'refusers', 'consumers' or 'survivors' are all terms used to describe people who may be eligible to access or actually access health care services ${ }^{1}$. 'Service users' is the term we will use throughout this piece for consistency and reflecting current orthodoxy, without necessarily conferring agreement with value. Many service users of mental health services will, as part of their treatment, be given a diagnosis of a mental health problem, however, it is useful to consider mental health problems on a continuum (Boullier \& Blair, 2018; DeLisi et al., 2017; Sweeney, Clement, Filson, \& Kennedy, 2016).

\footnotetext{
${ }^{1}$ Nurses will be referred to as such, other practitioners such as occupational therapists, psychologists, therapists, psychiatrists, social workers etc. will be referred to as healthcare practitioners. When considering the key papers; nurses and practitioners grouped together will be referred to as health care practitioners.
} 
Health care practitioners' roles are to work with the person, their strengths and needs rather than focus on a label, which may not tell you very much (Johnston et al., 2018).

Personality disorder is a diagnosis attracting particular criticism, with associated stigma; hence its usefulness has been questioned (Bolton, Lovell, Morgan, \& Wood, 2014), being described as the most ambiguous diagnostic category in psychiatry (Benedik \& Dobnik, 2014). Conversely, having a diagnosis of personality disorder can be useful for some in enabling access to appropriate services, helpful treatment, or welfare benefits (National Institute for Health and Care Excellence, 2016a, 2016b) or can help explain otherwise inexplicable feelings or responses (Bolton et al., 2014; Gillard, Turner, \& Neffgen, 2015). A term is also needed in order for research to be clearly focused and for the evidence base to grow (Claridge \& Davis, 2003). However, many argue that creating a formulation is a more useful tool than simple diagnosis (Houghton \& Jones, 2016). There are movements, particularly on social media which are anti-diagnosis altogether, viewing the terminology of personality disorder as offensive; such as a community of people who use the hashtag \#traumanotpd (also see PD in the bin (2018)). The term 'personality disorder' can cause service users to be stigmatised and excluded (Eren \& Şahin, 2016; National Institute for Mental Health In England, 2003), it can however, go deeper than this, causing trauma or re-traumatisation (Johnston et al., 2018). Indeed, many categories of mental distress, including the diagnosis of personality disorder can be seen as an understandable response to adverse experiences such as trauma (Boullier \& Blair, 2018; DeLisi et al., 2017; Sweeney et al., 2016) leading to the development of notions of trauma informed care (Sweeney et al., 2016). Haigh and Benefield (2019) have developed a general theory of human development with wider social appeal, beginning with learning gleaned from relational and democratising tendencies in clinical work with individuals who carry a diagnosis of personality disorder. Indeed, going back to the seminal paper by Main (1957) there has been an interest in the relational challenges of caring for this service user group, yet there is absence of literature on temporal aspects of salient nursing relationships for the following 50 years. 
Individuals who are studying to become registered mental health nurses across a variety of different courses in the UK spend substantial amount of their time allocated to clinical placements (Nursing and Midwifery Council, 2018) and, are, indeed, often the most visible and accessible worker to spend face to face time with service users (Jones \& Black, 2008). Nursing education across the globe has unique elements, for example in some countries students study a generic nursing programme rather than in specific fields of adult, child, learning disability and mental health (as in the UK) (Palmer, Hutchings, \& Leone, 2020). Students doing such courses complete mental health specific placements as part of their generic nursing programme (Happell, Moxham, \& Clarke, 2011).

When student nurses are on placement, in any country, they are expected to spend time with service users and support them towards their recovery. In the UK this is part of their completion of proficiencies for registered nurses (Nursing and Midwifery Council, 2018). Annex A of the UK Nursing and Midwifery Council standards is specific for communication and relationship management skills which are congruent to the themes identified in this review.

In the time service users and students spend together they may 'interact', 'engage' and develop a 'relationship'. It is also important to mention here that there may be a presumption made by other studies that every healthcare practitioner or student will develop a therapeutic/ helping relationship with every service user they spend time with, however this may not be the case. The exploration of lived experiences resonates with the lifeworld existentials; spatiality, temporality, relationality and corporality (Van Manen, 1990, 1997), which are congruent with the time shared between people, it is therefore important to recognise these shared experiences.

\section{METHODS}




\section{Search strategy}

An integrative review was chosen as the focus was across different areas (time, student mental health nurses, service users, and personality disorder) and methodologies. An integrative review utilises a systematic method and thorough search strategy (Noble \& Smith, 2018). Gildberg, Elverdam, and Hounsgaard (2010) note analysing findings from a spread of methods can have limitations. However, including diverse methodologies and analysis enables a comprehensive overview of the literature and understanding of the topic area (Haracz, Ryan, Hazelton, \& James, 2013; Whittemore \& Knafl, 2005). The review followed appropriate principles from Joanna Briggs standards (Lizarondo et al., 2017) and completion of a Preferred Reporting Items for Systematic Reviews and Meta-Analyses (PRISMA) (Moher, Liberati, Tetzlaff, \& Altman, 2009) (Table 4). Medical Subheadings [MeSH] terms were utilised to ensure the search strategy was robust. The notion of 'time' presented a lexicological challenge in selecting appropriately alike alternative search terms (see table 3). In addition to this, if the focus had been solely on either quantitative or qualitative studies, important and enlightening papers may have been missed, hence an integrative review was appropriate. Publications from peer-reviewed journals were reviewed and a quality appraisal tool was used. Databases searched are included in table 1. Inclusion and exclusion criteria were applied to ensure focus (see table 2). Searching was conducted from 1984 to the present, this date marking the commencement in the UK the so-called Project 2000 initiative which brought nurse education into universities (Le Var, 1997; McKenna, Davis, \& Williams, 2020).

\section{Databases searched}

Insert table 1 here.

$\underline{\text { Inclusion and exclusion criteria }}$ 
Insert table 2 here.

\section{$\underline{\text { Search terms }}$}

Insert table 3 here.

\section{FINDINGS}

\section{Search Outcome}

The 37 papers selected reviewed and discussed within the integrative review included: 23 qualitative papers with approaches: grounded theory (1), journal analysis (1), phenomenology (5), phenomenology discussion paper (1), interpretative phenomenology (4), content analysis (2), participatory research (1), qualitative-visual study (1) and generic qualitative methodology (7). There were 4 mixed methods, 3 cross sectional studies, 3 survey studies, 2 discussion papers, 1 qualitative review and 1 literature review. There were 15 studies completed in the UK, 5 in Sweden, 3 in South Africa, 4 in America, 3 in Australia, 1 in Canada, 1 in Turkey, 1 in the Netherlands, 2 in Denmark and 2 in Norway. The discussion and literature review papers (4 from the 37) were included in a separate key paper and quality appraisal process to ensure the robustness of the quality appraisal of this review, however they have been included in the discussions of themes as they provide interesting information that is important to review. The studies date from 1996 to 2020 with the majority being published between 2010-2019.

Eighteen of the studies were completed in mental health services (non-secure) not focused on personality disorder. 16 were focused on secure care: 3 of which looked specifically at personality disorder, another 2 papers also had service users with a diagnosis participating or practitioners who were working with service users with a diagnosis of personality disorder. 6 studies involved student nurses. 18 studies interviewed service users. 24 studies explored the 
therapeutic relationship either initially or it was identified as a theme. An additional 11 refer to interactions, communication or engagement. Only 1 paper specifically explored time as a concept however this came up in the results of 8 other papers.

\section{Data Analysis}

To ensure rigour, the three authors of this paper were involved in the thematic analysis (Braun \& Clarke, 2006) of the papers identified by the integrative review. This included a reflexive process throughout, including discussions of inclusion (Jensen \& Laurie, 2016).

Study eligibility flow diagram (PRISMA) (Moher et al., 2009)

Insert table 4 here.

Key papers table

Insert table 5 here.

Quality Appraisal

Quality appraisal is a process whereby the methodology, research design and findings from research studies are assessed critically for their quality, clarity and comprehensiveness of reporting (Petticrew \& Roberts, 2006). Walsh and Downe (2006) critical appraisal framework, based on a review of available quality frameworks and recognition of the complexities of metasynthesis, was utilised to review the research studies shortlisted (see table 6). This framework is designed primarily for the critical appraisal of qualitative studies, but is useful as part of an integrative review, being concise, robust, and flexible. 
Others have been criticised for being either too lengthy (Sandelowski \& Barroso, 2002; Spencer, Ritchie, Lewis, \& Dillon, 2003) or lacking in robustness (Critical Appraisal Skills Programme, 2014). It is, however, important to note, that there is no standardised tool free from limitations (Walsh \& Downe, 2006).

Each of the papers included in the review were appraised using the Walsh and Downe (2006) summary framework. We chose not to utilise the specific grading criteria (Downe, Simpson, \& Trafford, 2007), feeling it was important to apply common sense (Sandelowski \& Barroso, 2002) and take caution not to reject studies purely on a grading system (Pawson, 2006). We did, however, make a broad judgement of 'high', 'medium' or 'low' quality. In addition to this, due to the large area reviewed, some studies were discussion papers and quantitative papers and it was important not to dismiss them as their conclusions were of relevance.

\section{$\underline{\text { Quality appraisal table }}$}

Insert table 6 here.

\section{DISCUSSION}

In reviewing the key papers, a thematic analysis process identified four distinct but interrelated themes under which the reviewed studies will be discussed.

1. 'Psychosocial skills'

2. 'Relationships'

3. 'Environment'

'Impact of time' (overarching theme connecting 1-3)

\section{$\underline{\text { Thematic map }}$}


Insert table 7 here.

\section{Theme 1: Psychosocial skills}

The articles reviewed described a range of psychosocial skills all practitioners and therefore students need to practice. These skills include: maintaining thoughtful professional boundaries, and the development of self-awareness to monitor and manage the impact of countertransference and interpersonal style (Bowen \& Mason, 2012; Kurtz \& Turner, 2007; Scheick, 2011). Managing the impact of countertransference is of particular importance when supporting service users with a diagnosis of personality disorder (Kurtz \& Turner, 2007). A high proportion of service users carrying a personality disorder diagnosis are supported in secure services, as well as local inpatient settings (National Institute for Health and Care Excellence, 2016a, 2016b). Bowen and Mason (2012) and Kurtz and Turner (2007) differentiate skills needed in secure services compared to non-secure services (Cleary, Hunt, Horsfall, \& Deacon, 2012), emphasising skills to manage security, such as maintaining boundaries, rather than communication and personal skills, referred to in Cleary et al. (2012) review of acute adult services. However, Ketola and Stein (2013) found that if student nurses developed such listening, communication and self-reflection skills on their placements they were able to be empathic of service users thus enhancing the time spent together, which enabled the students to grow, personally and professionally.

Bowen and Mason (2012), although having a large sample of nurses completing their survey, did not explore the thoughts of service users about the skills needed by practitioners, as is missing from the other studies in this theme. Bowen and Mason (2012) also group 'personality disorder' with 'psychopathy' a questionable decision, though they do explore their rationale for this in the background. Kurtz and Turner (2007) further address requisite skills, as compared to Bowen's study, to explore necessary supportive systems in order for practitioners to cope, including coping with reported feelings of vulnerability. This includes good multidisciplinary 
working and group supervision utilising a reflective approach. Reflective discussion was recommended in Oostvogels, Bongers, and Willems (2018) study to enhance compassionate behaviour of practitioners working with service users with a personality disorder diagnosis.

Yildiz (2019) highlight students' need for supervision due to their encounter of communication barriers when caring for service users and experiencing the effects of countertransference. Having the skills to manage the impact of various interpersonal dynamics is common across both Kurtz and Turner (2007) and Scheick (2011) papers. Scheick (2011) complex mixed methodological study specifically considers the impact of countertransference in mental health services and how self-awareness and mindfulness are key areas for students to explore. In using a template designed by the author the students' ability to self-monitor countertransference was enhanced and had a positive effect on their learning and thus their practice.

\section{Theme 2: Relationships}

The second theme identified was Relationships. Such human relations are made through our communications and interactions with others in our lifeworld (Van Manen, 1997). Building relationships within mental health care, and especially in working with people with a personality disorder diagnosis, is vital. The articles' reviewed considered aspects of relationships such as attachment styles and seeing the person. Aiyegbusi and Kelly (2015) and Evans, Murray, Jellicoe-Jones, and Smith (2012) discuss the importance of practitioners being aware of attachment styles of the service users they are supporting, when building relationships. Aiyegbusi concluded that training should be accessed by practitioners to build resilience and increase awareness of attachment processes, which will enhance understanding of the service user. Indeed, developing an understanding of the service users is also important for student nurses (Johansson \& Martensson, 2019). Aiyegbusi integrated a Delphi study with a phenomenological approach with service user and practitioner 
participants. Some research phenomenologists would propose that phenomenology should not be part of a mixed method approach which risks detracting from the authentic nature of lived experience (Moran, 2000). However Mayoh and Onwuegbuzie (2015) argue that phenomenological methods work extremely well as a component of mixed methods research. Jenkins and Coffey (2002) also completed a mixed methodology approach highlighting the importance of the therapeutic relationship in often complex situations and how education and preparation should include reference to the value of this relationship. McAllister and McCrae (2017) ask for more emphasis of therapeutic engagement in nurse education. Rask and Brunt (2006) also recommend priority for skills training to promote effective interactions, aligning with theme one.

Bacha, Hanley, and Winter (2019) conclude that services should be focused more upon care rather than power and control. Equally, Evans et al. (2012) and Gildberg et al. (2010) found that being mindful of relationship security including managing risk and maintaining boundaries was significant. Evans et al. (2012) do, nonetheless, discuss the impact of seeing the person and being present when spending time with service users, which is also highlighted by Salzmann-Erikson, Rydlo, and Wiklund Gustin (2016), Shattell, Starr, and Thomas (2007) and Walsh (1999). Unlike Walsh, Langley and Klopper (2005) interviewed both service users and practitioners to ensure experienced were gained from both parties involved in the relationship. They highlighted trust as being a foundation for any relationship. Cameron, Kapur, and Campbell (2005) stress the importance of getting to know individuals, in addition to considering countertransference, for optimising therapeutic relationships between service users and nurses, improving interpersonal experiences.

Three of the studies explored student nurses experiences of the therapeutic relationship, including the importance of talking about 'normal stuff' (Johansson \& Martensson, 2019; Jones \& Wright, 2017; Looi, Savenstedt, \& Engstrom, 2016). It has been noted more broadly that service users often value ordinary talk and interaction (Cleary et al., 2012), and this may even 
be associated with distinct therapeutic gains (Lakey \& Orehek, 2011). New sociological interest in the mundane materialities of care emphasises the importance of such, often taken for granted, aspects of the everyday, and their impact on relationships (Brownlie \& Spandler, 2018; McKeown, 2019). Jones and Wright (2017) found that students' perceptions of building a relationship with service users carrying a personality disorder diagnosis was impacted upon by other practitioners. However, despite other practitioners 'clouding their judgment', the students saw the importance of seeing the person rather than the diagnosis. The students in Johansson and Martensson (2019) study also saw the value of getting to know the service user to create good relationships, which can only be done by spending time together.

\section{Theme 3: Environment}

The impact of the environment on interactions is important within mental health care to ensure service users feel valued and that students and practitioners have the time to spend with service users. In this sense, the environment comprises an amalgam of material and psychosocial attributes, or 'lived space' (spatiality) (Van Manen, 1997). Service users in two focus groups in the Long, Knight, Bradley, and Thomas (2012) study highlighted the importance of hope, engagement in treatment and developing a sense of self-worth as essential to a positive treatment milieu. Shattell, Andes, and Thomas (2008) found that a key environmental element relevant to nurses was the therapeutic relationship, as discussed in theme two, however the service users in the study did not discuss the relationship at all. The service users found that their caring experience was derived from other service users in their environment rather than nurses. Their experiences of the mental health unit were not described to be a 'therapeutic milieu'; service users felt bored, that their needs were unmet, and the environment was not only ineffective but harmful. These findings align with Mollerhoj and Os Stolan (2018) study, in the theme 'Impact of time' (below), where service users felt dehumanised. In Horberg, Sjogren, and Dahlberg (2012) study, service users were lacking meaningful relationships and having to adapt to demands of practitioners, viewed as 'non- 
caring', despite a compassionate approach being a central component to the Nursing and Midwifery Council proficiencies for UK nurses (Nursing and Midwifery Council, 2018).

Though the respective caring environments are complex, internationally there are certain common features, spanning US (Shattell et al., 2008) Australia (Cleary \& Edwards, 1999), UK (Chandley, 2000; Long et al., 2012; Reavey et al., 2019) and Sweden (Horberg et al., 2012). Cleary and Edwards (1999) found both service users and nurses identified that because nurses are busy, other pressing tasks take time away from relational support. These findings intersect with Chandley (2000) enquiry into the impact of the experience of passage of time in a secure hospital for service users and practitioners; with the time practitioners spend with service users objectified as a commodity. In Looi et al. (2016) and colleagues' Swedish study the provision of nursing care based on therapeutic relationships need not be a challenging task, but it takes place in a complex environment with a propensity to make easy things complicated. Reavey et al. (2019) concludes that by increasing a greater sense of physical movement and liberty there can be improvements in the therapeutic landscape, and thus reversal of any effects of narrowing service users' sense of agency. Environments and activities in these environments should be designed based on mapping of relations and service users' experiences.

\section{Impact of time}

Service users emphasise the importance of trust, empathy, understanding of historical experiences, and positive perceptions and interactions in their experiences of care. Bressington, Stewart, Beer, and MacInnes (2011) and Lord, Priest, and McGowan (2016) both refer to the impact a positive social environment can have for service users (Shattell et al., 2008) which ultimately aids in the development of therapeutic relationships (Long et al., 2012) and higher levels of satisfaction of their care. Other factors that enhanced service users' satisfaction were honesty, care and interest from practitioners (Maclnnes, Courtney, 
Flanagan, Bressington, \& Beer, 2014) and a recovery-focused approach that conveyed hope and sense of common humanity by dual sharing of self (Borg \& Kristiansen, 2004). In contrast to such approaches, Wright, Haigh, and McKeown (2007) refer to dehumanising factors affecting those carrying a personality disorder diagnosis. This aligns with the experiences of service users in secure services, as explored by Mollerhoj and Os Stolan (2018) who found that service users in secure services specifically, can feel dehumanized and monstrous, and other commentators on secure care have noted practitioners may react in ways that reflect such constructions of the monstrous other (Jacob, Gagnon, \& Holmes, 2009). Interestingly Borg and Kristiansen (2004) use the term 'humanity' as does Walsh (1999). In this context, humanity implies factors such as just being with people, sharing common ground, being human, and respectfully recognising and responding to difference (Rashed, 2019; Wright et al., 2007). The respective authors suggest such basic human concern for service users and associated support and interaction should be at the forefront of any student, nurse/ practitioner and service user encounter, as referred to by Mollerhoj and Os Stolan (2018) and Eldal et al. (2019) who's participants were service users. The service users in Eldal's study stated the impact of being recognised as a person. Walsh interviewed nurses, not service users, limiting full understanding of the encounter as only exploring one side of the relationship.

The service users in Borg and Kristiansen (2004) study discuss developing relationships based on 'common factors', which is also noted in the theme relationships (Jones \& Wright, 2017). Service user participants in the Schafer and Peternelj-Taylor (2003) study offered a multidimensional view of time. The time nurses spent with them was perceived as indicating a measure of their personal value. They also felt time was used by the practitioners to assert their power, mirroring aspects of Chandley (2000) findings regarding temporality. Certainly, Van Manen (1997) offers reflection that the way we experience constraints and demands imposed by time can influence how we feel. 
Muller and Poggenpoel (1996) found that interactions with nurses promoted 'good mental health' in the service users. The majority of the above studies were focused on service users' experience of care from nurses, explored mainly with interviews, with the exception of Maclnnes et al. (2014) and Bressington et al. (2011) who completed surveys. Although useful as a research approach, it may be useful to combine surveys with other more qualitative methodologies to allow for an exploration of issues in detail (Munro \& Baker, 2007). Particularly when exploring a person's experiences, interviews can enable participants to voice their experiences (Marshall \& Rossman, 2011; Peyrovi, Yadavar-Nikravesh, Oskouie, \& Bertero, 2005).

Mukumbang and Adejumo (2014) explored service users' experiences of being cared for by student nurses, which considered how they identified the students, for example by their badges or if they introduced themselves; and their perceptions of them whether positive or negative because of this. Their experiences varied greatly, though self-introduction was seen as important. Mukumbang and Adejumo (2014) highlight that previous studies exploring interactions between service users and students have focused on the experience of students rather than service users.

\section{$\underline{\text { CONCLUSIONS }}$}

This integrative review highlights that matters of trust, empathy, understanding of historical experiences, positive perceptions and interactions with students and healthcare practitioners are deemed important for all service users, not just those who carry a personality disorder diagnosis. The impact of the environment on those interactions can have both negative and positive implications, especially relational components of the environment. In addition to this, the skills needed for students, in services, including being mindful of professional boundaries, and impact of countertransference and interpersonal style are also evident in the literature. 
A positive environment with consideration of time and focus on seeing the person, can lead to the development of therapeutic relationships with service users carrying a diagnosis of personality disorder. Student nurses attempting to build such relationships need to be mindful of service users and their own attachment experiences, as well as the impact these can have on experiences of countertransference. It is important for student nurses and healthcare practitioners to be aware of the supportive impact of positive environments and how doing 'everyday stuff' can bolster recognition and identity; making a person feel human in potentially dehumanising places.

This review marshals contributions to knowledge, potentially illuminating of student preparation/ education in appropriate skills. Such impacts are relevant for wider nursing education, particularly given the focus on communication skills and relationship building in the Nursing and Midwifery Council proficiencies in the UK, and thus, this review has broader reach than the specific groups identified (service users carrying a personality disorder diagnosis and student mental health nurses). In addition, the review identifies no papers that have addressed the lived experiences of students and service users and the time they share together on personality disorder units, suggesting an area in need of enquiry. Further research could aid the protection of vulnerable novice practitioners and ultimately improve the experience and outcomes of care for service users.

\section{$\underline{\text { REFERENCES }}$}

Aiyegbusi, A., \& Kelly, D. (2015). 'This is the pain I feel!' Projection and emotional pain in the nurse-patient relationship with people diagnosed with personality disorders in forensic and specialist personality disorder services: findings from a mixed methods study. Psychoanalytic Psychotherapy, 29(3), 276-294. doi:10.1080/02668734.2015.1025425

Bacha, K., Hanley, T., \& Winter, L. A. (2019). 'Like a human being, I was an equal, I wasn't just a patient': Service users' perspectives on their experiences of relationships with staff in mental health services. Psychology Psychotherapy: Theory, Research Practice.

Benedik, E., \& Dobnik, S. C. (2014). Phemenological aspects of personality disorders in adult psychiatric patients. Psychiatria Danubina, 26(2), 127-136.

Bolton, W., Lovell, K., Morgan, L., \& Wood, H. (2014). Meeting the Challenge: Making a difference. 
http://www.emergenceplus.org.uk/images/Documents/meeting-the-challenge-makinga-difference-practitioner-guide.pdf.

Borg, M., \& Kristiansen, K. (2004). Recovery-oriented professionals: Helping relationships in mental health services. Journal of Mental Health, 13(5), 493-505.

Boullier, M., \& Blair, M. (2018). Adverse childhood experiences. Paediatrics and Child Health, 28(3), 132-137.

Bowen, M., \& Mason, T. (2012). Forensic and non-forensic psychiatric nursing skills and competencies for psychopathic and personality disordered patients. Journal Of Clinical Nursing, 21(23-24), 3556-3564. doi:https://dx.doi.org/10.1111/i.13652702.2011.03970.x

Bowers, L., Alexander, J., Simpson, A., Ryan, C., \& Carr-Walker, P. (2007). Student psychiatric nurses' approval of containment measures: relationship to perception of aggression and attitudes to personality disorder. International Journal of Nursing Studies, 44(3), 349-356. doi:https://dx.doi.org/10.1016/j.ijnurstu.2005.03.002

Braun, V., \& Clarke, V. (2006). Using thematic analysis in psychology. Qualitative Research in Psychology, 3, 77-101.

Bressington, D., Stewart, B., Beer, D., \& Maclnnes, D. (2011). Levels of service user satisfaction in secure settings - A survey of the association between perceived social climate, perceived therapeutic relationship and satisfaction with forensic services. International Journal of Nursing Studies, 48(11), 1349-1356. doi:10.1016/j.jnurstu.2011.05.011

Brownlie, J., \& Spandler, H. (2018). Materialities of mundane care and the art of holding one's own. Sociology of Health and IIIness, 40(2), 256-269.

Cameron, D., Kapur, R., \& Campbell, P. (2005). Releasing the therapeutic potential of the psychiatric nurse: a human relations perspective of the nurse-patient relationship. Journal of Psychiatric \& Mental Health Nursing, 12(1), 64-74. doi:10.1111/j.13652850.2004.00796.x

Chandley, M. (2000). Time and confinement: Towards a common sense of socio-temporality in a special hospital. The British Journal of Forensic Practice, 2(2), 30-37.

Claridge, G., \& Davis, C. (2003). Personality and psychological disorders. London, United Kingdom: Arnold.

Cleary, \& Edwards, C. (1999). 'Something always comes up': nurse-patient interaction in an acute psychiatric setting. Journal of Psychiatric \& Mental Health Nursing, 6(6), 469477.

Cleary, Hunt, G., Horsfall, J., \& Deacon, M. (2012). Nurse-Patient Interaction in Acute Adult Inpatient Mental Health Units: a Review and Synthesis of Qualitative Studies. Issues In Mental Health Nursing, 33(2), 66-79. doi:10.3109/01612840.2011.622428

Critical Appraisal Skills Programme. (2014). Critical Appraisal Skills Programme: Making sense of evidence. Retrieved from https://casp-uk. net/wpcontent/uploads/2018/01/CASP-Qualitative-Checklist-2018.pdf

DeLisi, M., Alcala, J., Kusow, A., Hochstetler, A., Heirigs, M. H., Caudill, J. W., . . Baglivio, M. T. (2017). Adverse childhood experiences, commitment offense, and race/ethnicity: are the effects crime-, race-, and ethnicity-specific? International journal of environmental research and public health, 14(3), 331.

Downe, S., Simpson, L., \& Trafford, K. (2007). Expert intrapartum maternity care: A metasythesis. Journal of Advanced Nursing, 57(2), 127-140.

Eldal, K., Natvik, E., Veseth, M., Davidson, L., Skjølberg, Å., Gytri, D., \& Moltu, C. (2019). Being recognised as a whole person: A qualitative study of inpatient experience in mental health. Issues In Mental Health Nursing, 40(2), 88-96.

Eren, N., \& Şahin, S. (2016). An evaluation of the difficulties and attitudes mental health professionals experience with people with personality disorders. Journal Of Psychiatric And Mental Health Nursing, 23(1), 22-36. doi:10.1111/jpm.12257

Evans, K., Murray, C. D., Jellicoe-Jones, L., \& Smith, I. (2012). Support staffs' experiences of relationship formation and development in secure mental health services. British Journal of Forensic Practice, 14(2), 104-115. doi:10.1108/14636641211223666 
Gildberg, F. A., Elverdam, B., \& Hounsgaard, L. (2010). Forensic psychiatric nursing: a literature review and thematic analysis of staff-patient interaction. Journal of Psychiatric \& Mental Health Nursing, 17(4), 359-368. doi:https://dx.doi.org/10.1111/i.1365-2850.2009.01533.x

Gillard, S., Turner, K., \& Neffgen, M. (2015). Understanding recovery in the context of lived experience of personality disorders: a collaborative, qualitative research study. BMC Psychiatry, 15, 183. doi:https://dx.doi.org/10.1186/s12888-015-0572-0

Haigh, R., \& Benefield, N. (2019). Towards a unified model of human development. Mental Health Review Journal, 24(2), 124-132. doi:10.1108/MHRJ-11-2018-0038

Happell, B., Moxham, L., \& Clarke, K. A. (2011). Implementation of a major in mental health nursing in Australian universities. International Journal of Mental Health Nursing, 20(4), 237-246.

Haracz, K., Ryan, S., Hazelton, M., \& James, C. (2013). Occupational therapy and obesity: An integrative literature review. Australian Occupational Therapy Journal, 60(5), 356356.

Hörberg, U., Brunt, D., \& Axelsson, Å. (2004). Clients' perceptions of client- nurse relationships in local authority psychiatric services: A qualitative study. International Journal of Mental Health Nursing, 13(1), 9-17.

Horberg, U., Sjogren, R., \& Dahlberg, K. (2012). To be strategically struggling against resignation: the lived experience of being cared for in forensic psychiatric care. Issues In Mental Health Nursing, 33(11), 743-751. doi:https://dx.doi.org/10.3109/01612840.2012.704623

Houghton, K., \& Jones, E. (2016). To formulate or not to formulate? A case study. British Journal of Mental Health Nursing, 5(6), 274-281. doi:10.12968/bjmh.2016.5.6.274

Jacob, J. D., Gagnon, M., \& Holmes, D. (2009). Nursing so-called monsters: On the importance of abjection and fear in forensic psychiatric nursing. Journal of Forensic nursing, 5(3), 153-161.

Jenkins, E., \& Coffey, M. (2002). Compelled to interact: forensic community mental health nurses' and service users' relationships. Journal of Psychiatric \& Mental Health Nursing, 9(5), 553-562.

Jensen, E. A., \& Laurie, C. (2016). Doing real research: A practical guide to social research. London, United Kingdom: SAGE.

Johansson, B., \& Martensson, L. B. (2019). Ways of strategies to knowing the patient described by nursing students. Nurse Education in Practice, 38, 120-125. doi:https://dx.doi.org/10.1016/..nepr.2019.06.003

Johnston, L., Boyle, M., Cromby, J., Dillon, J., Harper, D., Kinderman, P., . . Read, J. (2018). The power threat meaning framework: Towards the identification of patterns in emotional distress, unusual experiences and troubles or troubling behaviour, as an alternative to functional psychiatric diagnosis. Leicester, UK: The British Psychological Society.

Jones, \& Black. (2008). Involving mental health service users in student education. Retrieved from https://www.nursingtimes.net/involving-mental-health-service-users-in-studenteducation/1735557. article

Jones, \& Wright, K. (2017). "They're really PD today": An exploration of mental health nursing students' perceptions of developing a therapeutic relationship with patients with a diagnosis of antisocial personality disorder. International journal of offender therapy and comparative criminology, 61(5), 526-543. doi:10.1177/0306624X15594838

Ketola, J., \& Stein, J. V. (2013). Psychiatric clinical course strengthens the student-patient relationships of baccalaureate nursing students. Journal of Psychiatric \& Mental Health Nursing, 20(1), 23-34. doi:https://dx.doi.org/10.1111/i.1365-2850.2012.01878.x

Kurtz, A., \& Turner, K. (2007). An exploratory study of the needs of staff who care for offenders with a diagnosis of personality disorder. Psychology \& Psychotherapy: Theory, Research \& Practice, 80(3), 421-435. doi:https://dx.doi.org/10.1348/147608306X171510 
Lakey, B., \& Orehek, E. (2011). Relational regulation theory: a new approach to explain the link between perceived social support and mental health. Psychological Review, 118(3), 482.

Langley, G. C., \& Klopper, H. (2005). Trust as a foundation for the therapeutic intervention for patients with borderline personality disorder. Journal Of Psychiatric And Mental Health Nursing, 12(1), 23-32.

Le Var, R. (1997). Project 2000: A newpreparation for practice- Has policy been realized? Part I. Nurse Education Today, 17(3), 171-177. doi:https://doi.org/10.1016/S02606917(97)80129-3

Lizarondo, L., Stern, C., Carrier, J., Godfrey, C., Rieger, K., Salmond, S., . . . H, L. (2017). Mixed methods systematic reviews. In A. E \& M. Z (Eds.), Joanna Briggs Institute Reviewer's Manual. https://reviewersmanual.joannabriggs.org/ The Joanna Briggs Institute.

Long, C. G., Knight, C., Bradley, L., \& Thomas, M. (2012). Effective therapeutic milieus in secure services for women: the service user perspective. Journal of Mental Health, 21(6), 567-578. doi:https://dx.doi.org/10.3109/09638237.2012.734649

Looi, G. M., Savenstedt, S., \& Engstrom, A. (2016). "Easy but not simple": Nursing students' descriptions of the process of care in a psychiatric context. Issues In Mental Health Nursing, 37(1), 34-42. doi:https://dx.doi.org/10.3109/01612840.2015.1085607

Lord, K., Priest, H., \& McGowan, A. (2016). Therapeutic engagement in medium-secure care: An interpretative phenomenological analysis of service users' experiences. Journal of $\begin{array}{llll}\text { Forensic Psychiatry \& Psychology, 27(1), 55-76. } & \text {. }\end{array}$ doi:10.1080/14789949.2015.1090622

Maclnnes, D., Courtney, H., Flanagan, T., Bressington, D., \& Beer, D. (2014). A cross sectional survey examining the association between therapeutic relationships and service user satisfaction in forensic mental health settings. BMC Research Notes, 7, 657-657. doi:10.1186/1756-0500-7-657

Main, T. (1957). The Ailment. British Journal of Medical Psychology, 30, 9.

Marshall, C., \& Rossman, G. B. (2011). Designing qualitative research (5th ed.). London, United Kingdom: SAGE.

Mayoh, J., \& Onwuegbuzie, A. J. (2015). Toward a Conceptualization of Mixed Methods Phenomenological Research. Journal of Mixed Methods Research, 9(1), 91-107. doi:10.1177/1558689813505358

McAllister, S., \& McCrae, N. (2017). The therapeutic role of mental health nurs es in psychiatric intensive care: A mixed-methods investigation in an inner-city mental health service. Journal Of Psychiatric And Mental Health Nursing, 13, 13. doi:https://dx.doi.org/10.1111/ipm.12389

McKenna, L., Davis, J., \& Williams, E. (2020). Nursing and Midwifery Education: Historical Perspectives. Clinical Education for the Health Professions: Theory and Practice, 118.

McKeown, M., Thomson, G., Scholes, A., Edgar, F., Downe, S., Price, O., Baker, J., Greenwood, P., Whittington, R. \& Duxbury, J. (2019). Restraint minimisation in mental health care: legitimate or illegitimate force? An ethnographic study. Sociology of Health and IIIness, 42, 449-464.

Moher, D., Liberati, A., Tetzlaff, J., \& Altman, D. G. (2009). Preferred reporting items for systematic reviews and meta-analyses: The PRISMA statement. Annals of internal medicine, 151(4), 264-269.

Mollerhoj, J., \& Os Stolan, L. (2018). 'First and foremost a human being...': User perspectives on mental health services from 50 mentally disordered offenders. Nordic Journal of Psychiatry, 72(8), 593-598.

Moran, D. (2000). Introduction to Phenomenology. London, United Kingdom: Routledge.

Morgan, S., \& Sanggaran, R. (1997). Client-centred approach to student nurse education in mental health practicum: an inquiry. Journal Of Psychiatric And Mental Health Nursing, 4(6), 423-434. 
Mukumbang, F. C., \& Adejumo, O. (2014). Patients' experiences of being nursed by student nurses at a teaching hospital. Curationis, 37(1), 1230. doi:https://dx.doi.org/10.4102/curationis.v37i1.1230

Muller, A., \& Poggenpoel, M. (1996). Patients' internal world experience of interacting with psychiatric nurses. Archives of Psychiatric Nursing, 10(3), 143-150.

Munro, S., \& Baker, J. A. (2007). Surveying the attitudes of acute mental health nurses. Journal Of Psychiatric And Mental Health Nursing, 5(1), 3-19.

National Institute for Health and Care Excellence. (2016a). Antisocial behaviour and conduct disorders in children and young people. Retrieved from https://pathways.nice.org.uk/pathways/antisocial-behaviour-and-conduct-disordersin-children-and-young-people

National Institute for Health and Care Excellence. (2016b). Borderline personality disorder: recognition and management. Retrieved from https://www.nice.org.uk/quidance/cq78

National Institute for Mental Health In England. (2003). No longer a diagnosis of exclusion. Retrieved from https://www.personalitydisorder.org.uk/wp-content/.../PD-No-longer-adiagnosis-of-exclusion.pdf

Noble, H., \& Smith, J. (2018). Reviewing the literature: Choosing a review design. Evidence Based Nursing, 21(2), 39-41.

Nursing and Midwifery Council. (2018). Standards for pre-registration nursing education. Retrieved from https://www.nmc.org.uk/globalassets/sitedocuments/educationstandards/programme-standards-nursing.pdf

Oostvogels, I., Bongers, I. L., \& Willems, A. (2018). The role of emotion regulation, coping, self-reflection and insight in staff interaction with patients with a diagnosis of personality disorder in forensic settings. journal of Psychiatric Mental Health Nursing, 25(9-10), 582-600.

Palmer, B., Hutchings, R., \& Leone, C. (2020). Laying foundations: Attitudes and access to mental health nurse education. Retrieved from https://www.nuffieldtrust.org.uk/research/laying-foundations-attitudes-and-access-tomental-health-nurse-education

Pawson, R. (2006). Digging for nuggets: How 'bad' research can yield 'good' evidence. International Journal of Social Research Methodology, 127-142.

PD in the bin. (2018). PD in the bin. Retrieved from https://recoveryinthebin.org/2016/02/25/pd-in-the-bin-facebook-group/

Petticrew, M., \& Roberts, H. (2006). Systematic reviews in the social sciences. Oxford, United Kingdom: Blackwell.

Peyrovi, H., Yadavar-Nikravesh, M., Oskouie, S. F., \& Bertero, C. (2005). Iranian student nurses' experiences of clinical placement. International Nursing Review, 52(2), 134141. doi:https://dx.doi.org/10.1111/i.1466-7657.2005.00417.x

Rashed, M. (2019). Madness and the demand for recognition: A philosophical inquiry into identity and mental health activism. Oxford, UK: Oxford University Press.

Rask, M., \& Brunt, D. (2006). Verbal and social interactions in Swedish forensic psychiatric nursing care as perceived by the patients and nurses. International Journal of Mental Health Nursing, 15(2), 100-110.

Reavey, P., Brown, S. D., Kanyeredzi, A., McGrath, L., Tucker, I. J. S. s., \& medicine. (2019). Agents and spectres: Life-space on a medium secure forensic psychiatric unit. 220 , 273-282.

Salzmann-Erikson, M., Rydlo, C., \& Wiklund Gustin, L. (2016). Getting to know the person behind the illness - the significance of interacting with patients hospitalised in forensic psychiatric settings. Journal Of Clinical Nursing, 25(9-10), 1426-1434. doi:10.1111/jocn.13252

Sandelowski, M., \& Barroso, J. (2002). Handbook for synthesizing qualitative research. New York, NY: Springer.

Schafer, P., \& Peternelj-Taylor, C. (2003). Therapeutic relationships and boundary maintenance: the perspective of forensic patients enrolled in a treatment program for violent offenders. Issues In Mental Health Nursing, 24(6/7), 605-625. 
Scheick, D. M. (2011). Developing self-aware mindfulness to manage countertransference in the nurse-client relationship: an evaluation and developmental study. Journal of Professional Nursing, $27(2)$, 114-123. doi:https://dx.doi.org/10.1016/..profnurs.2010.10.005

Shattell, M. M., Andes, M., \& Thomas, S. P. (2008). How patients and nurses experience the acute care psychiatric environment. Nursing Inquiry, 15(3), 242-250. doi:https://dx.doi.org/10.1111/i.1440-1800.2008.00397.x

Shattell, M. M., Starr, S. S., \& Thomas, S. P. (2007). 'Take my hand, help me out': mental health service recipients' experience of the therapeutic relationship. International Journal of Mental Health Nursing, 16(4), 274-284. doi:https://dx.doi.org/10.1111/j.1447-0349.2007.00477.x

Spencer, L., Ritchie, J., Lewis, J., \& Dillon, L. (2003). Quality in qualitative evaluation: A framework for assessing research evidence. Retrieved from http://www.civilservice.gov.uk/wpcontent/uploads/2011/09/a quality framework tcm6-38740.pdf

Sweeney, A., Clement, S., Filson, B., \& Kennedy, A. (2016). Trauma-informed mental healthcare in the UK: What is it and how can we further its development? Mental Health Review Journal, 21(3), 174-192.

Van Manen, M. (1990). Beyond assumptions: Shifting the limits of action research. Theory into practice, 29(3), $152-157$.

Van Manen, M. (1997). Researching lived experience: Human science for an action sensitive pedagogy. London, United Kingdom: The Althouse Press

Walsh. (1999). Shared humanity and the psychiatric nurse-patient encounter. The Australian And New Zealand Journal Of Mental Health Nursing, 8(1), 2-8. Retrieved from http://search.ebscohost.com/login.aspx? direct=true\&db=cmedm\&AN=10382394\&site $=$ ehost-live

Walsh, \& Downe. (2006). Appraising the quality of qualitative research. Midwifery, 22(2), 108119.

Walton, J., \& Blossom, H. (2013). The experience of nursing students visiting older adults living in rural communities. Journal Of Professional Nursing: Official Journal Of The American Association Of Colleges Of Nursing, 29(4), 240-251. doi:10.1016/j.profnurs.2012.05.010

Whittemore, R., \& Knafl, K. (2005). The integrative review: Updated methodology. Journal of Advanced Nursing, 52(5), 546-553.

Wright, K., Haigh, K., \& McKeown, M. (2007). Reclaiming the humanity in personality disorder. International Journal of Mental Health Nursing, 16(4), 236-246.

Yildiz, E. (2019). What do nursing students tell us about their communication with people with mental illness? A qualitative study. Journal of the American Psychiatric Nurses Association. doi:1078390319892311 